\title{
ENSAIO DE VARIEDADES DE CAFEEIROS III
}

\author{
J. E. Teixeira Mendes
}

Engenheiro agrônomo, Seçãa de Café, Instituto Agronômico de Campinas

\section{1 - INTRODLÇ̃̃O}

O ensaio de variedades de cafeeiros iniciado na Estação Experimental Central de Campinas, em 1931, teve seus primeiros resultados publicados em 1939, em Boletim Técnico dêste Instituto (1).

A continuação da experiência foi divulgada em "Bragantia" (2), atingindo os resultados até o ano de 1946.

No presente trabalho examinaremos o prosseguimento dêsse ensaio, em seu conjunto, e em relação aos anos de 1947, 1948, 1949 e 1950. Teremos, assim, o confronto das variedades em estudo durante dezesseis colheitas.

O plano de ensaio é o mesmo já relatado nas duas publicações anteriores. As variedades que o constituem são as seguintes :

1 - Café Nacional - Coffea arabica I. var. typica Cramer

2 - Café Amarelo de Botucatu - Coffea arabica L. var. typica Cramer forma xanthocarpa (Caminhoá) Krug

3 - Café Bourbon - Coffea arabica L. var. bourbon (B. Rodr.) Choussy

4 - Café Bourbon amarelo - Coffea arabica L. var. Bourbon (B. Rodr.) Choussy forma xanthocarpa K. M. C.

5 - Café Sumatra - Coffea arabica L. var. typica Cramer

6 - Café Maragogipe - Coffea arabica L. var. maragogipe Hort. ex Froehner

\section{2 - ADUBACÕES E TRATOS CULTLRAIS}

As adubações continuaram a ser dadas anualmente, e cova por cova, para maior uniformidade nas condições do ensaio. As doses de adubos empregados foram :

ANo DE 1947

gramas

Estêreo

Torta de algodão.

Fosfato potássico

ANo DE $1948 \quad$ gramas

Palha de café

Farinha de ossos

Salitre do Chile 200

Cloreto de potássio . 
Estêrco

Cloreto de potássio

Salitre do Chile

ANo DE $1950 \quad$ gramas

Estêrco _.

Torta de algodão

Superfosfato _...

Cloreto de potássio .

Os tratos culturais foram os normais em uma bem cuidada lavoura de café : capinas regulares, desbrota, ligeira limpeza das árvores para a retirada de galhos secos, etc. $\mathrm{O}$ contrôle à erosão continua a ser feito por um sistema de curvas de nível, que funciona a contento.

\section{3-COLHEITA E RESULTADOS OBTIDOS ATE 1946}

A colheita tem sido realizada dentro do limite do possível, tantas vêzes quantas necessárias para se colhêr caf́é maduro.

A média de produção, por variedade, nas doze primeiras colheitas (1935-1946), foi a seguinte, expressa em café em côco e por filleira de 50 plantas :

VARIEDADES

Produção em $\mathrm{kg}$

Bourbon amarelo

120,86

Bourbon

113,52

Sumatra

97,21

Nacional

76,77

Amarelo de Botucatu

75,74

Maragogipe

71,73

\section{4 - RESULTADOS OBTIDOS DE 1947 A 1950}

\section{1 - COLHEITA DE 1947}

a) Produção total - A produção dêste ano foi das menores verificadas em todo o decurso do ensaio. E verdade que esta colheita sucede a uma das maiores já obtidas. O quadro 1 dá uma relą̧ão da colhei ta média das cinco repetições de cada uma das variedades.

QUadro 1.-Produçōes médias das variedades em 1947

\begin{tabular}{|c|c|c|c|}
\hline \multirow{2}{*}{ Variedade ol. forma } & \multicolumn{3}{|c|}{ Produção de café } \\
\hline & Cereja & Ein côco & Beneficiado \\
\hline $\begin{array}{l}\text { Bourbon amarelo } \\
\text { Bourbon } \\
\text { Sumatra } \\
\text { Maragogipe } \\
\text { Nacional } \\
\text { Amarelo de Botucatu }\end{array}$ & $\begin{array}{r}k g \\
164,400 \\
149,840 \\
129,320 \\
108,520 \\
89,120 \\
66,700\end{array}$ & $\begin{array}{r}k g \\
71,280 \\
66,640 \\
61,280 \\
\mathbf{4 7 , 3 4 0} \\
\mathbf{4 3 , 4 4 0} \\
30,820\end{array}$ & $\begin{array}{rr} \\
\\
36,900 \\
34,070 \\
33,370 \\
25,480 \\
23,490 \\
1.6,300\end{array}$ \\
\hline
\end{tabular}


O Bourbon amarelo foi o mais produtivo, vindo em seguida o Bourbon vermelho e em terceiro lugar o Sumatra. A variedade Maragogipe, apesar de ter dado colheita bem menor do que as três anteriores, colocou-se acima do Nacional e do Amarelo de Botucatu. A produção dêste último foi insignificante.

b) Época de maturação dos frutos - A colheita foi feita em duas épocas. Infelizmente, por dificuldade em se obter braço operário suficiente para todos os trabalhos experimentais com o cafeeiro, a $1 .^{\mathrm{a}}$ colheita foi realizada muito tardiamente ( 20 a 25 de maio), quando a quase totalidade dos frutos já se achava madura. Por isso, não se pôde observar a marcha do amadurecimento do café para as diversas variedades, pela percentagem de frutos maduros em cada uma das colheitas. Para a variedade Maragogipe, no entanto, evidencia-se o retardamento da maturação, como se verifica no quadro 2.

QuAdro 2.-Produções e percentagens de café cereja nas duas colheitas das variedades em 1947

\begin{tabular}{|c|c|c|c|c|}
\hline \multirow{3}{*}{ Variedade ou forma } & \multicolumn{4}{|c|}{ Produção de café cereja } \\
\hline & \multicolumn{2}{|c|}{ Em pêso } & \multicolumn{2}{|c|}{ Em percentagem } \\
\hline & 1.a colheita & 2.s colheita & 1.a colheita & 2.2 colheita \\
\hline & $k g$ & $k g$ & $k g$ & $k g$ \\
\hline Amarelo de Botueatu & 63,620 & 3,080 & 95,38 & 4,61 \\
\hline Sumatra & 120,220 & 9,100 & 92,96 & 7,03 \\
\hline Nacional ... & 80,960 & 8,160 & 90,84 & 9,15 \\
\hline Bourbon -.- & 132,200 & 17,640 & 88,22 & 17,77 \\
\hline Bourbon amarelo & 141,000 & 23,600 & 85,66 & 14,33 \\
\hline Maragogipe & 41,120 & 67,400 & 37,89 & 62,10 \\
\hline
\end{tabular}

$\mathrm{Na}$ primeira colheita, realizada de 20 a 25 de maio, tôdas as variedades. apresentavam mais de oitenta por cento de frutos maduros, ao passo que - Maragogipe apenas podia dar cêrca de 38 por cento. A segunda colheita, realizada de 27 de junho a $1 .^{\circ}$ de julho, representou apenas uma catação para tôdas as outras variedades e o grosso da colheita para o Maragogipe.

c) Tamanho das sementes - Foi feito o estudo da peneira média (3) das variedades em confronto. Adotando-se o resultado obtido das amostras da maior colheita para tôdas as variedades, temos a seguinte classificação :

VARIEDADE OU FORMA

Peneira média.

Maragogipe

Nacional

Amarelo de Botucatu

17,49

Sumatra

Bourbon 
As sementes de maior tamanho são as do Maragogipe; o Nacional, o Amarelo de Botucatu e o Sumatra produziram sementes de tamanho aproximadamente igual e maiores do que as dos dois Bourbons.

\section{2 - COLHEITA DH 1948}

a) Produęão total - A produção dêste ano foi das melhores obtidas no decorrer dêste ensaio. O quadro 3 dá a indicação de como se comportaram as variedades.

Qtiadro 3.-Produçós médias das variedades em 1948

\begin{tabular}{|c|c|c|c|}
\hline \multirow{2}{*}{ Variedade ou formu } & \multicolumn{3}{|c|}{ Produção de caf́! } \\
\hline & Cereja & Em cóco & Beneficiado \\
\hline & log & ko & $k: g$ \\
\hline Bourbon amarelo $\ldots$. & 574,580 & 237,600 & 118.870 \\
\hline Bourbon _...... & 423,920 & 175,060 & 84,660 \\
\hline Sumatra $\ldots . .$. & 386,360 & 163,040 & 84,420 \\
\hline Maragogipe & 325,180 & 161,900 & 87,120 \\
\hline Nuciottal _. & 280,560 & 120,580 & 59,020 \\
\hline Amarelo de Botucat!1 $\ldots . .$. & 258,520 & 110,680 & $53,03 n$ \\
\hline
\end{tabular}

O Bourbon amarelo produziu bem mais do que qualquer das outras variedades ou formas; em scgundo lugar se colocou o Bourbon, seguido de perto pelo Sumatra e Maragogipe. O Nacional e o Amarelo de Botucatu produziram bem menos do que tôdas as demais variedades. E interessante de se notar que esta foi a maior produção do Bourbon amarelo em todo o decurso do ensaio. As ontras variedades, apesar de produzirem bem, já tiveram anos de colheitas mais fartas, como se vê no quadro 4.

Qradro 4.-Produções de café cm côeo das variedades em estudo, nos anos em que foram idênticas ou maiores que as de 1948, as quais foram tomadas como têrmo de comparação

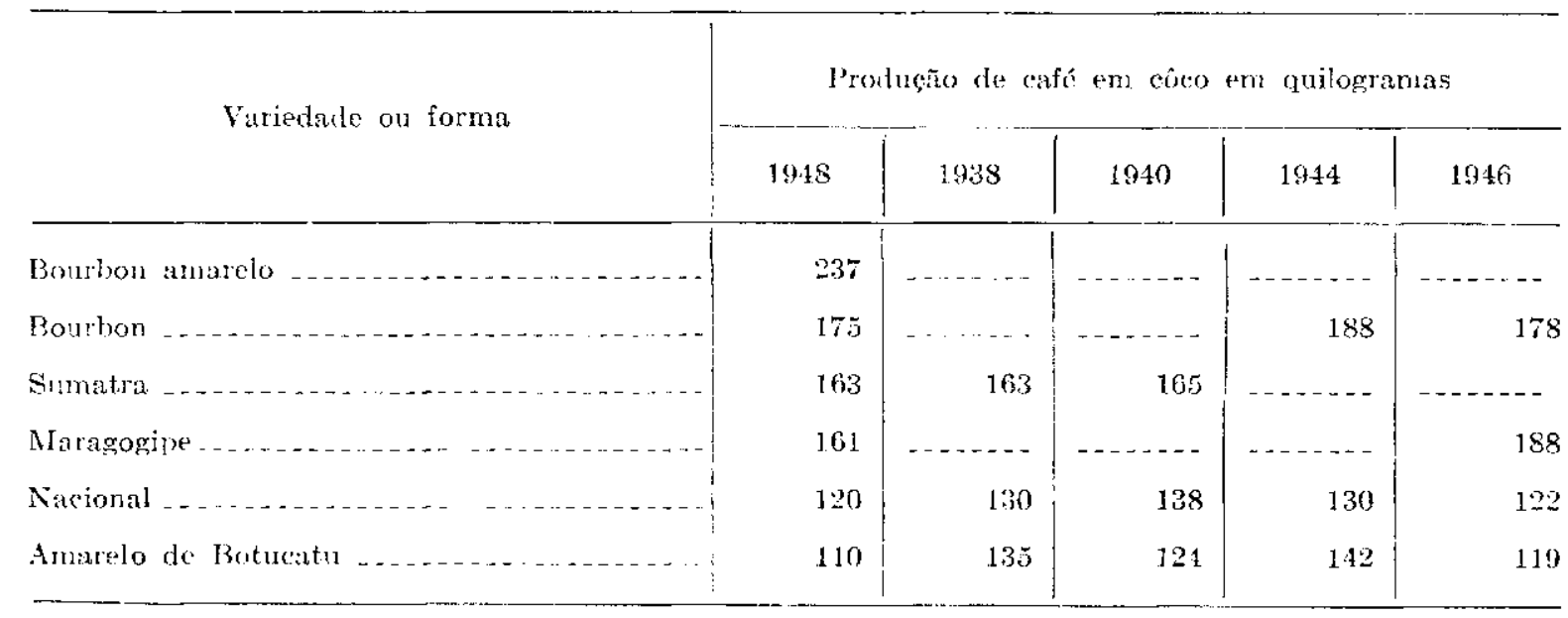


$\mathrm{Na}$ primeira coluna dêsse quadro vem anotada a produção média de café em côco no ano de 1948 ; nas colunas seguintes, as produções médias obtidas pelas diversas variedades nos anos em que elas foram idênticas ou maiores do que a de 1948.

Observa-se que a de 1948 foi a maior produçã́o até agora obtida pela variedade Bourbon amarelo; a variedade Bourbon vermelho, em apenas dois anos, produziu mais do que em 1948 ; fato idêntico ocorreu com o Sumatra ; o Maragogipe apenas em um ano deu produção maior. Com o Nacional e o Amarelo de Botucatu houve maior número de anos em que a produção foi maior que a de 1948.

De modo geral, no entanto, pode-se dizer que o ano de 1948 foi um dos melhores para as produções das diversas variedades do ensaio.

b) Época de maturação dos frutos - A colheita foi efetuada em três épocas, sendo necessária mais uma para a variedade Maragogipe, que, na primeira, ainda estava com quase todos os frutos verdes. A época de cada uma delas foi a seguinte : $1 .^{\text {a }}$ colheita, 1 a 16 de abril ; $2 .^{\mathrm{a}}$ colheita, 8 a 28 de maio ; $3 .^{a}$ colheita, 19 de junho a 8 de julho; $4 .^{a}$ colheita, 19 de agôsto.

$\mathrm{O}$ quadro 5 mostra as percentagens de frutos maduros em cada colheita.

QUADro 5.-Produçóes e percentagens de café cereja nas diversas colheitas das variedades em 1948

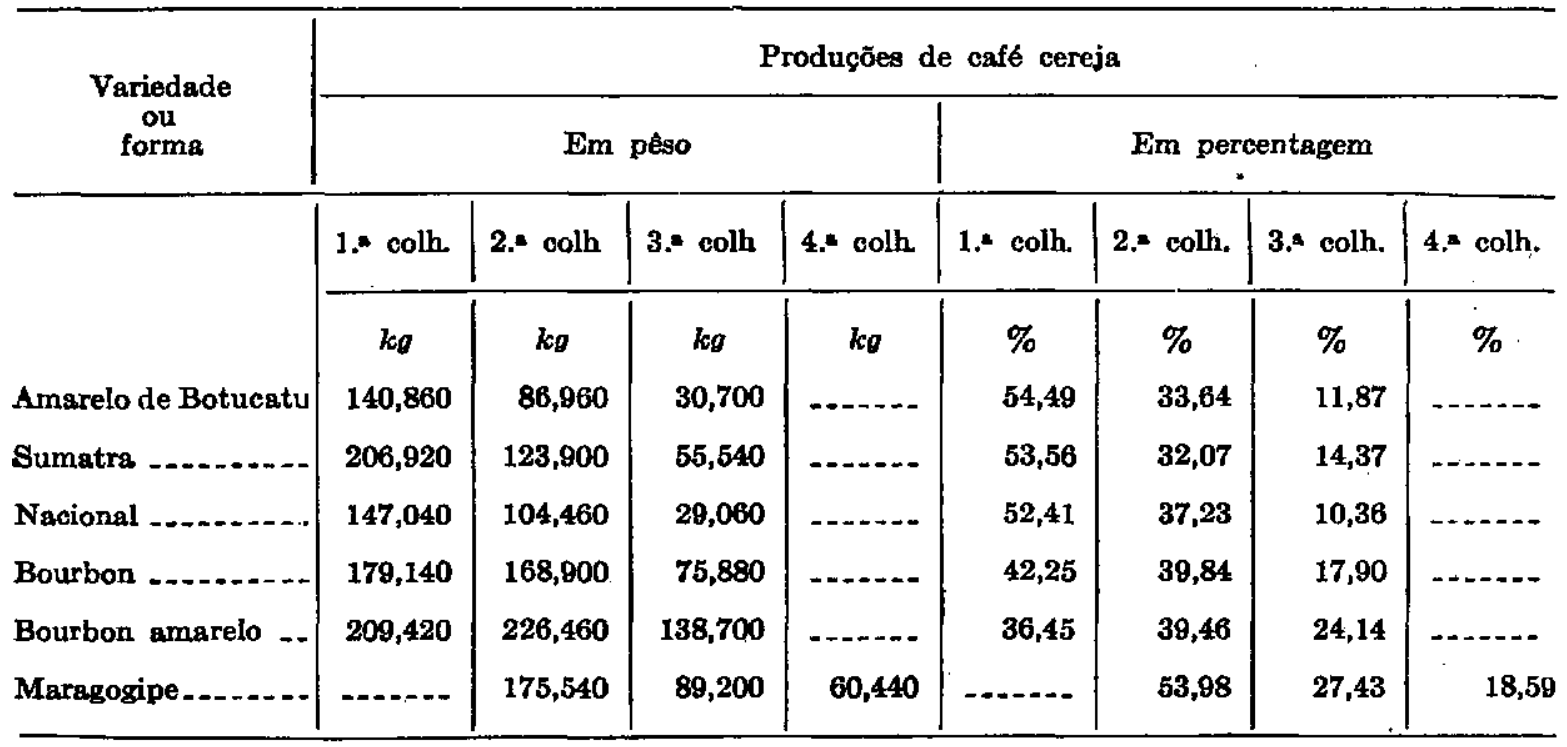

O amarelo de Botucatu foi o mais precoce, seguido, muito de perto, pelo Sumatra e Nacional ; o Bourbon foi um pouco mais tardio do que êstes ; o Bourbon amarelo mais tardio ainda e o Maragogipe o mais tardio de todos, sòmente dando a primeira colheita cêrca de um mês depois das demais.

c) Tamanho das sementes $-O$ cálculo da peneira média da $10^{\mathrm{a}}$ e 2. ${ }^{\mathrm{a}}$ colheitas deu o resultado seguinte: 
Maragogipe

Amarelo de Botucatu

Sumatra

Nacional

As maiores sementes foram produzidas pelo Maragogipe ; o Amarelo de Botucatu, das demais variedades, foi o que as apresentou de maior tamanho ; o Sumatra e o Nacional vêm em seguida e as menores foram as do Bourbon amarelo e Bourbon.

\section{3 - COLHEITA DE 1949}

a) Produção total - A produção dêste ano, em comparação com a do anterior, foi bem menor para tôdas as variedades. O resultado obtido foi o que vem no quadro 6 .

Quadno 6.-Produções médias das variedades em 1949

\begin{tabular}{|c|c|c|c|}
\hline \multirow{2}{*}{ Variedade ou forma } & \multicolumn{3}{|c|}{ Produgăo de Café } \\
\hline & Cereja & Em cốco & Beneficiado \\
\hline & ko & ko & $\mathrm{kg}$ \\
\hline Bourbon aunarelo & 276,600 & 124,350 & 57,510 \\
\hline Bourhon ........... & 260,320 & 117,880 & 53,720 \\
\hline Sumatra & 170,500 & 79,960 & 38,540 \\
\hline Nacional . . . . . . & 142,600 & 68,880 & 34,230 \\
\hline Amarelo de Botucatu & 134,100 & 67,020 & 32,170 \\
\hline Maragngipe & 72,980 & 34,120 & 17,290 \\
\hline
\end{tabular}

Em primeiro lugar colocou-se o Bourbon amarelo, seguido, muito de perto, pelo Bourbon ; em terceiro lugar, com boa diferença para com aquêles, figura o Sumatra, e, muito próximo dêste, o Nacional ; abaixo dêste, o Amarelo de Botucatu ; finalmente, em último plano, o Maragogipe, com uma produção muito reduzida.

b) Época de maturação dos frutos - Foram efetuadas apenas duas colheitas para cada uma das variedades. O Maragogipe, na $1 .^{a}$ colheita, não tinha ainda frutos maduros em quantidade suficiente, motivo pelo qual, só na 2. ${ }^{\mathrm{a}}$ colheita do ensaio, é que apresenta dados. Foi feita uma terceira colheita, só para essa variedade. As épocas foram as seguintes: $1 .^{a}$ colheita, 13 a 22 de abril ; $2 .^{a}$ colheita, 30 de maio a 4 de junho ; $3 .^{n}$ colheita, 8 de julho.

Os resultados que aparecem no quadro, dão uma idéia de como se processou o amadurecimento nas diversas variedades. 
Quadro 7.-Produções e percentagens de café cereja nas diversas colheitas das variedades em 1949

\begin{tabular}{|c|c|c|c|c|c|c|}
\hline \multirow{3}{*}{ Variedude ou forma } & \multicolumn{6}{|c|}{ Produçaes de café cereja } \\
\hline & \multicolumn{3}{|c|}{ Em peso } & \multicolumn{3}{|c|}{ Em percentagem } \\
\hline & 1.* Colh. & 2.* Colb. & 3. Colb. & 1. Colh. & 2.s Colh. & 3.A Colh. \\
\hline , & $k g$ & $k \boldsymbol{k g}$ & $k g$ & $\%$ & $\%$ & $\%$ \\
\hline Amarelo de Botucatu & 98,660 & 35,440 & 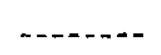 & 73,57 & 26,43 & 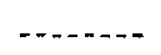 \\
\hline Sumatra .... & 123,920 & 46,580 & $\cdots$ & 72,68 & 27,32 & $\ldots$ \\
\hline Nacional . . . . & 102,600 & 40,000 & 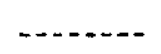 & 71,95 & 28,05 &.- \\
\hline Bourbon & 157,680 & 102,640 & $\ldots$ & 60,57 & 39,43 & $\ldots$ \\
\hline Bourbon amarelo -. & 149,200 & 127,400 & 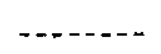 & 53,94 & 46,06 & $\ldots$ \\
\hline Maragogipe ...... & 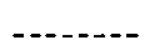 & 26,320 & 46,660 & $-2 \ldots$ & 36,06 & 63,93 \\
\hline
\end{tabular}

Neste ano reproduziu-se exatamente a mesma disposição das variedades, relativamente ao amadurecimento dos frutos. O precoce foi o Amarelo de Botucatu ; o Sumatra e o Nacional apresentaram percentagem quase idêntica de frutos maduros, na primeira colheita, à daquele ; os dois Bourbons foram mais tardios ; finalmente, o Maragogipe somente na segunda colheita das demais variedades é que pôde ter pequena percentagem de frutos em condições de serem colhidos.

c) Tamanho das sementes - A semente produzida neste ano foi de tamanho muito pequeno. A relação abaixo dá a peneira média obtida nas duas colheitas.

VARIEDADE OU FORNA

Peneira média

Maragogipe

Nacional

Amarelo de Botucatu

Sumatra

Bourbon amarelo

16,18

Bourbon

16,10

Como sempre, o Maragogipe produziu as maiores sementes ; o Nacional, das demais variedades, foi o que as apresentou de maior tamanho ; seguiu-se o Amarelo de Botucatu e Sumatra com café quase idêntico ; em último lugar, com as menores sementes, vêm ambos os Bourbons.

\section{4 - COLHEITA DE 1950}

a) Produção total - Neste ano, a produção de tôdas as variedades foi grande. $O$ resultado da colheita vem expresso no quadro 8. 
QUADRo 8.-Produções médias das variedades em 1950

\begin{tabular}{|c|c|c|c|}
\hline \multirow{2}{*}{ Variedsde ou forma } & \multicolumn{3}{|c|}{ Produçăo de café } \\
\hline & Cereja & Em côco & Beneficiado \\
\hline & $k g$ & $\mathrm{~kg}$ & $\mathrm{~kg}$ \\
\hline Bourbon amarelo ................. & 501,540 & 204,020 & 102,080 \\
\hline Sumatra & 419,160 & 182,500 & 95,440 \\
\hline Maragogipe & 344,580 & 160,680 & 79,090 \\
\hline Bourbon & 354,340 & 145,140 & 69,430 \\
\hline Nacional & 302,980 & 128,180 & 67,820 \\
\hline Amarelo de Botucatu .... & 301,780 & 123,520 & 63,300 \\
\hline
\end{tabular}

A maior produção foi obtida pelo Bourbon amarelo ; o segundo lugar coube ao Sumatra ; vem em seguida o Maragogipe, que sobrepujou o Bourbon; finalmente, os menos produtivos foram o Nacional e o Amarelo de Botucatu.

b) Época da maturação dos frutos - Foram feitas duas colheitas para cada uma das variedades. Na primeira colheita não havia frutos maduros do Maragogipe em quantidade suficiente para que fôsse ela realizada. Por isso, quando tôdas as outras foram colhidas pela segunda vez, fêz-se a primeira colheita daquela variedade e, finalmente, uma última sòmente para a retirada de seus últimos frutos. As épocas foram as seguintes : $1 .^{\mathrm{a}}$ colheita, 12 a 23 de maio; $2 .^{\mathrm{a}}$ colheita, 6 a 21 de junho; 3. ${ }^{*}$ colheita, 20 de julho.

As percentagens de frutos maduros, em cada uma delas, vêm expressas no quadro 9.

QUADro 9.-Produções e percentagens de café cereja nas colheitas das diversas varicdades em 1950

\begin{tabular}{|c|c|c|c|c|c|c|}
\hline \multirow{3}{*}{ Variedade ou forma } & \multicolumn{6}{|c|}{ Produção de café cereja } \\
\hline & \multicolumn{3}{|c|}{ Em pêso } & \multicolumn{3}{|c|}{ Em percentagem } \\
\hline & 1.* Colh. & 2.A Colb. & 3.s Colh. & 1.* Colh. & 2. Colh. & 3. A Colh. \\
\hline & $k g$ & $k \sigma$ & $\mathrm{kg}$ & $\%$ & $\%$ & $\%$ \\
\hline Sumatra & 254,620 & 164,540 & $\ldots \ldots$ & 60,74 & 39,25 & \\
\hline Amarelo de Botucatu & 178,120 & 123,660 & $\ldots-\ldots$ & 59,02 & 40,98 & $\ldots$ \\
\hline Bourbon & 203,520 & 150,820 & $\ldots$ & 57,44 & 42,56 & -........ \\
\hline Nacional & 164,350 & 138,620 & $-\cdots$ & 54,25 & 45,75 & \\
\hline Bourbon amarelo & 216,720 & 284,820 & $-\cdots--$ & 43,21 & 56,79 & - n \\
\hline Maragogipe & - n. & 285,560 & 59,020 & 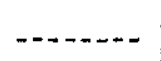 & 82,87 & 17,13 \\
\hline
\end{tabular}


O Sumatra foi o mais precoce, quase em igualdade de condiçres com o Amarelo de Botucatu ; em terceiro lugar, vem o Bourbon, seguido de perto pelo Nacional ; o Bourbon amarelo, das variedades colhidas, foi o que apresentou menor percentagem de frutos maduros em maio; nessa ocasião, o Maragogipe ainda não pôde ser colhido, sòmente vindo a ser, pela primeira vez, em junho.

c) Tamanho das sementes - Damos a seguir a relação média das peneiras obtidas na primeira e segunda colheitas.

VARIEDADE OU FORMA

Peneira média

Maragogipe

20,29

Amarelo de Botucatu

17,07

Nacional

17,04

Bourbon

16,81

Sumatra

16,79

Bourbon amarelo

16,73

De novo, a maior peneira média foi do Maragogipe ; em seguida, vem o Amarelo de Botucatu e Nacional, com sementes quase do mesmo tamanho ; em quarto lugar, aparece o Bourbon que, neste ano, as produziu maiores que as do Sumatra ; finalmente, o Bourbon amarelo foi o que apresentou sementes de menor tamanho.

\section{5 - CONCLUSÕES}

\section{1 - MATURAÇÃO DOS FRUTOS}

Examinando-se, ano por ano, a colocação das variedades quanto ao amadurecimento dos frutos, como vem indicado no quadro 10 , verifica-se o seguinte :

a) O Amarelo de Botucatu foi a variedade mais precoce em três dos quatro anos estudados;

b) O Sumatra ocupou o segundo lugar, também em três dos quatro anos ;

c) O Nacional colocou-se em terceiro lugar, em três dos quatro anos;

d) O Bourbon vermelho colocou-se em quarto lugar, em três dos quatro anos;

e) O Bourbon amarelo colocou-se em quinto lugar em todos os quatro anos;

f) O Maragogipe colocou-se em último lugar em todos os quatro anos, sendo a variedade mais tardia.

Ésses resultados confirmam os obtidos nos anos anteriores já relatados. 
Quadro 10.-Precocidade de maturação. Colocação das variedades segundo a maior percentagem de café cereja na 1." colheita, nos diversos anos

\begin{tabular}{|c|c|c|c|c|}
\hline \multirow{2}{*}{ Ordem de precocidade } & \multicolumn{4}{|c|}{ Posição das variedades nos anos de } \\
\hline & 1947 & 1948 & 1949 & 1950 \\
\hline $1 \ldots \ldots$ & Am. Botucatu & Am. Botucatu & Am. Botucatu & Sumatra \\
\hline 2.- & Sumatra & Sumatra & Sumatra & Am. Botucatu \\
\hline 3...-- & Nacional & Nacional & Nacional & Bourbon \\
\hline 4 & Bourbon & Bourbon & Bourbon & Nacional \\
\hline 5 & Bourhon am. & Bourbon am. & Bourbon am. & Bourbon am. \\
\hline 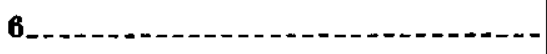 & Maragogipe & Maragogipe & Maragogipe & Maragogipe \\
\hline
\end{tabular}

\section{2 - TAMANHO DAS SEMENTES}

Examinando-se os resultados relativos à peneira média obtida nos quatro anos em aprêço, chegamos aos resultados demonstrados pelo quadro 11 :

Quadro 11.-Valores da peneira média para as diversas variedades, demonstrados, ano por ano, no período $1947-50$

\begin{tabular}{|c|c|c|c|c|c|}
\hline Variedade ou forma & 1947 & 1948 & 1949 & 1950 & Média \\
\hline Bourbon & 17,08 & 16,67 & 16,10 & 16,81 & 16,66 \\
\hline Bourbon amarelo & 17,16 & 16,94 & 16,18 & 16,73 & 16,75 \\
\hline Sumatra & 17,46 & 17,28 & 16,43 & 16,79 & 16,99 \\
\hline Amarelo de Botucatu ... & 17,49 & 17,41 & 16,47 & 17,07 & 17,11 \\
\hline Nacional ... & 17,53 & 17,14 & 16,59 & 17,04 & 17,22 \\
\hline Maragogipe_._- & 20,09 & 20,02 & 18,42 & 20,29 & 19,70 \\
\hline
\end{tabular}

Verifica-se que :

a) a variedade Maragogipe foi a que produziu sementes de maior tamanho em todo o período examinado ;

b) os dois Bourbons foram as variedades que apresentaram menor tamanho de semente em todo o período considerado ;

c) O Nacional, o Amarelo de Botucatu e o Sumatra se colocaram em situação intermediária entre o Maragogipe e os dois Bourbons.

\section{3 - PRODUÇĀO}

O quadro 12 dá a produçâo em café em côco, de tôdas as variedades, ano por ano, no período de 1935-1950.

Examinando-se o quadro 12 e a figura 1, verifica-se que tôdas as variedades foram aumentando as produções de 1935 a 1938. Daí em diante, tôdas elas, com exceção do Maragogipe, depois de uma colheita grande, 


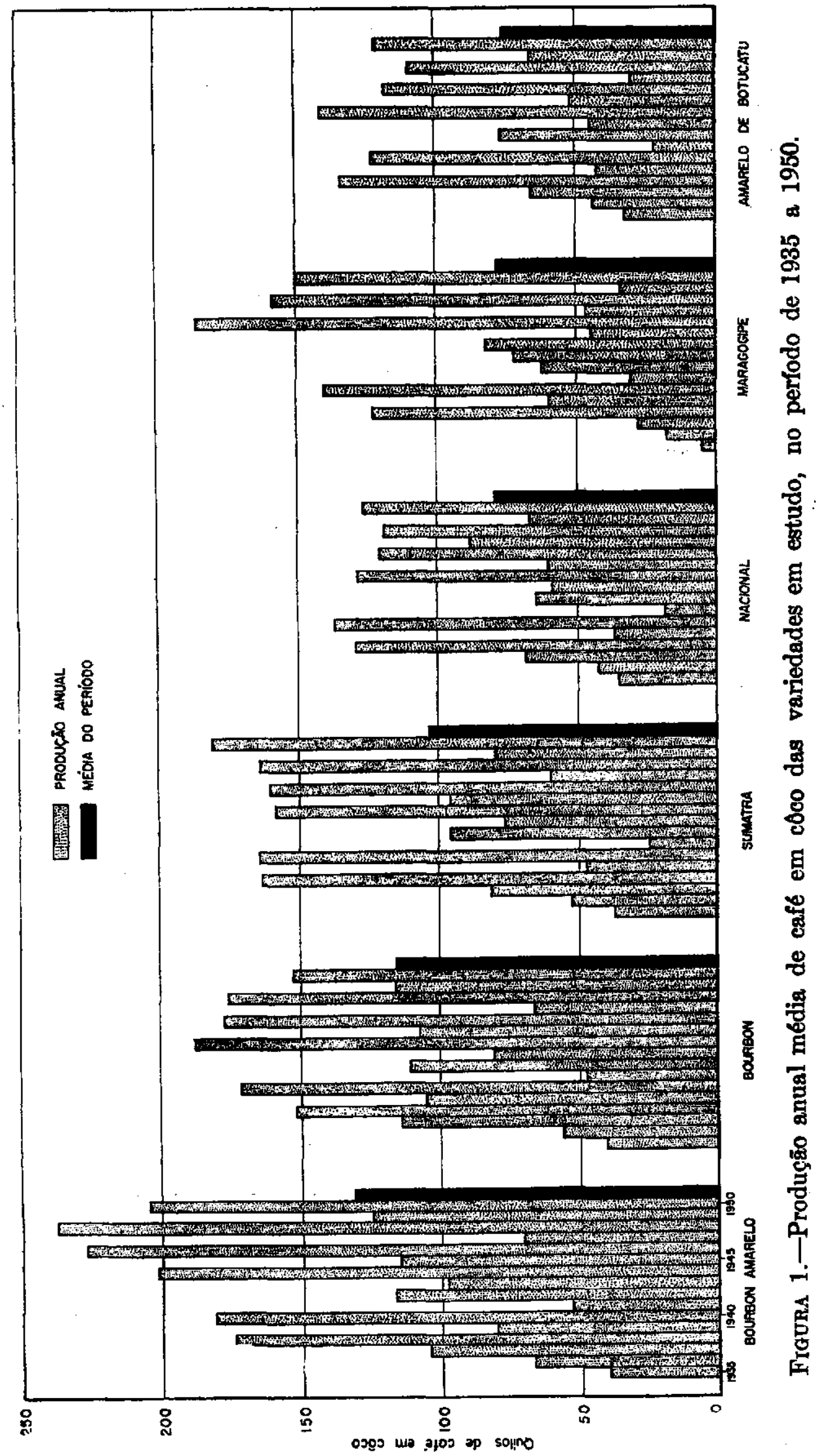


Quadro 12.-Produçóes médias de café em côco das diversas variedades, no período de $1935-1950$

\begin{tabular}{|c|c|c|c|c|c|c|}
\hline \multirow{2}{*}{ Anos } & \multicolumn{6}{|c|}{ Variedade ou forma } \\
\hline & $\begin{array}{l}\text { Bourbon } \\
\text { amarelo }\end{array}$ & Bourbon & Sumatra & Nacional & Maragogipe & $\begin{array}{c}\text { Amarelo } \\
\text { de } \\
\text { Botucatu }\end{array}$ \\
\hline & $k g$ & $k g$ & $\mathrm{~kg}$ & $k g$ & $k g$ & $k g$ \\
\hline 1935 & 39,18 & 39,18 & 38,88 & 36,62 & 5,47 & 33,00 \\
\hline $1936 \ldots$ & 66,09 & 56,87 & 53,41 & 42,89 & 18,18 & 44,54 \\
\hline $1937 \ldots$ & 104,74 & 113,28 & 82,35 & 70,44 & 28,17 & 07,81 \\
\hline 198 & 173,50 & 168,38 & 163,01 & 130,41 & 123,38 & 135,66 \\
\hline j939 & 80,67 & 102,55 & 47,87 & 38,87 & 60,70 & 43,60 \\
\hline $1940 \ldots$ & 180,56 & 170,40 & 165,52 & 138,18 & 140,02 & 124,78 \\
\hline $1941 \ldots$ & 51,98 & 47,40 & 24,90 & 19,50 & 31,04 & 22,12 \\
\hline $1942=-$ & 114,93 & 110,06 & 96,34 & 66,54 & 63,60 & 78,25 \\
\hline 1943 & $\mathbf{9 7 , 5 8}$ & 80,18 & 77,52 & 61,50 & 73,30 & 45,24 \\
\hline $1944 \ldots$ & 200,39 & 188,04 & 159,89 & 130,57 & 83,54 & 142,20 \\
\hline 1945 & 114,54 & 107,27 & 96,01 & 63,38 & 45,47 & 52,58 \\
\hline 1946 & 226,20 & 178,64 & 160,88 & 122,40 & 188,00 & 119.12 \\
\hline 1947 & 71,28 & 66,64 & 61,28 & 43,44 & 47,34 & 30,82 \\
\hline 1948 & 237,60 & 175,06 & 163,04 & 120,58 & 161,90 & 110,68 \\
\hline 1949. & 124,35 & 117,88 & 79,96 & 68,88 & 34,12 & 67,02 \\
\hline $1950 \ldots$ & 204,02 & 145,14 & 182,50 & 128,18 & 150,68 & 123,52 \\
\hline Média :- & 130,48 & 116,37 & 103,55 & 80,15 & 78,43 & 77,56 \\
\hline
\end{tabular}

sempre apresentaram uma de proporções bem menores. O Maragogipe seguiu êste mesmo ritmo no período de 1938 a 1942 . Depois desta safra apresentou duas outras com maior volume de produção (1943 a 1944). Daí em diante esta variedade apresentou ainda, mais pronunciadamente que as outras, a variação de colheitas, isto é, uma muito grande, seguida de outra muito pequena.

Pela média de produção do período todo (1935-1950), a variedade mais produtiva foi o Bourbon amarelo. Em segundo lugar, colocou-se o Bourbon, vindo em terceiro o Sumatra. Finalmente, quase em igualdade de condições, ficaram as três últimas variedades: Nacional, Maragogipe e Amarelo de Botucatu. Torna-se interessante notar que o Maragogipe já não é a última variedade em produção média no periodo todo, tendo já sobrepujado o Amarelo de Botucatu. A figura 1 representa a produção média de cada uma das variedades nesse período.

Se dividirmos o período de 16 anos (1935-1950) em quatriênios, e obtivermos as médias de produção, vamos ter os dados do quadro 13.

Quadro 13.-Produções médias de café em côco por quatriênios, para as seis variedades estudadas

Produção média por $\mathbf{5 0}$ plantase

\begin{tabular}{|c|c|c|c|c|}
\hline \multirow{2}{*}{ 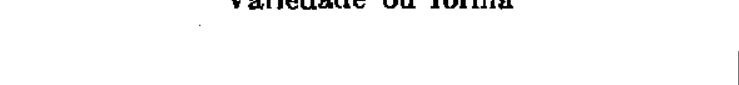 } & \\
\hline & 1935-1938 & $1939-1942$ & $1943-1946$ & $1947-1950$ \\
\hline $\begin{array}{l}\text { Bourbon amarelo } \\
\text { Bourbon } \\
\text { Sumatra } \\
\text { Amarelo de Botucatu } \\
\text { Nacional } \\
\text { Maragogipe }\end{array}$ & $\begin{array}{l}\mathbf{k g} \\
95,87 \\
94,45 \\
84,42 \\
70,27 \\
70,07 \\
43,82\end{array}$ & $\begin{array}{r}k g \\
107,03 \\
107,60 \\
83,66 \\
67,19 \\
65,77 \\
73,84\end{array}$ & $\begin{array}{l}k g \\
159,68 \\
138,53 \\
123,36 \\
89,78 \\
94,46 \\
97,57\end{array}$ & $\begin{array}{r}k g \\
159,31 \\
126,18 \\
121,70 \\
83,01 \\
90,27 \\
98,51\end{array}$ \\
\hline
\end{tabular}


Os resultados do primeiro quatriênio já foram estudados em trabalho anterior (1). Os dois seguintes foram examinados em outra publicação (2).

No período 1935-1938, as variedades se classificaram da seguinte maneira :

1. Bourbon amarelo Bourbon

2. Sumatra

3. Amarelo de Botucatu Nacional

4. Maragogipe

No segundo quatriênio (1939-1942), as variedades se dispuseram na seguinte ordem :

1. Bourbon

Bourbon amarelo

2. Sumatra

3. Maragogipe

Amarelo de Botucatu

Nacional

No terceiro período (1943-1946) começa o Bourbon amarelo a demonstrar uma nítida vantagem sôbre o Bourbon ; o Sumatra é o terceiro colocado ; o Maragogipe produz mais do que o Nacional e o Amarelo de Botucatu. A classificação das variedades é a seguinte :

1. Bourbon amarelo

2. Bourbon

3. Sumatra

4. Maragogipe

Nacional

Amarelo de Botucatu

Finalmente, no último quatriênio (1947-1950), acentua-se ainda mais a diferença existente entre o Bourbon amarelo e o Bourbon vermelho, pois, ao passo que o primeiro mantém produção idêntica à do período anterior, o segundo apresenta decréscimo ; o Sumatra mantém, pràticamente, a mesma produção ; fato idêntico ocorre com o Maragogipe ; o Nacional e o Amarelo de Botucatu também apresentam menores médias.

\section{6 - ANALLISE RSTATÍSTICA}

Feita a análise dos dados do ensaio (4) ficou demonstrado o seguinte :

a) existe diferença significativa entre a produção do Bourbon amarelo e a do Bourbon vermelho, sendo o Bourbon amarelo mais produtivo;

b) existe diferença significativa entre a produção do Bourbon vermelho e a do Sumatra;

c) existe diferença significativa entre a produção do Sumatra e a do Maragogipe, Nacional e Amarelo de Botucatu ; 
d) não existe diferença significativa entre a produção do Maragogipe, Nacional e Amarelo de Botucatu;

e) o aumento médio de colheita, por ano, da variedade Bourbon amarelo, é maior que o do Bourbon vermelho;

f) o aumento médio de colheita, por ano, do Maragogipe, é maior que o do Nacional, e o do Amarelo de Botucatu.

\section{RESTMO}

O ensaio de variedades de cafeeiros foi iniciado na Estação Experimental Central de Campinas, em 1931. A primeira colheita foi realizada em 1935. Em 1939, foi feita a publicação dos resultados referentes ao periodo 1935-38. Em 1949, nova publicação reuniu os dados do período 1935-46.

No presente trabalho vêm relatados os acontecimentos relativos aos anos que decorreram de 1947 a 1950 , ano por ano, e feito o exame dos resultados no período todo, desde o início da produção (1935-1950).

O ensaio teve prosseguimento normal nos anos de 1947 a 1950 . Foram feitas as adubações adequadas, as capinas se realizaram $\mathrm{cm}$ ordem, as colheitas se processaram regularmente bem.

A produção média foi examinada ano por ano, verificando-se que, nesse período, o Bourbon amarelo sempre se colocou no primeiro lugar. Tôdas as demais variedades tiveram alterações de colocação na competição de produção.

No período em exame (1947-1950), a variedade mais produtiva foi o Bourbon amarelo, seguida pelo Bourbon vermelho, Sumatra, Maragogipe, Nacional e Amarelo de Botucatu.

Com relação ao amadurecimento dos frutos, a variedade mais precoce foi o Amarclo de Botucatu, seguido pelo Sumatra, Nacional, Bourbon vermelho, Bourbon amarelo e, finalmente, o Maragogipe, que foi o mais tardio.

A variedade que apresentou sementes de maior tamanho foi o Maragogipe ; o Nacional, o Amarelo de Botucatu e o Sumatra produziram sementes de tamanho intermediário e o Bourbon vermelho e o Bourbon amarelo as de menor tamanho.

A análise dos dados referentes ao período todo do ensaio (1935-1950), isto é, dezesseis colheitas, demonstraram o seguinte :

a) existe diferença significativa entre a produção do Bourbon amarelo e a do Bourbon vermelho; sendo o Bourbon amarelo mais produtivo;

b) existe diferença significativa entre a produção do Bourbon vermelho e a do Sumatra;

c) existe diferença significativa entre a produção do Sumatra e a do Maragogipe, Nacional e Amarelo de Botucatu;

d) não existe diferença significativa entre a produção do Maragogipe, Nacional e Amarelo de Botucatu ;

e) o aumento médio de colheita, por ano, da variedade Bourbon amarelo, é maior do que o do Bourbon vermelho;

f) o aumento médio de colheita, por ano, do Maragogipe, é maior que o do Nacional e o do Amarelo de Botucatu. 


\section{S U M M A $\mathbf{Y}$}

The coffee varietal trial was initiated at the Campinas Experimental Station in 1931. The first harvest was gathered in 1935. The results for the period 1935-38 were published in 1939 and the united results for 1935-46, in 1949.

The present paper describes the individual observations for the years 1947 to 1950 and examines the results for the whole period from the beginning (1935-1950). The trial proceeded normally in the years 1947-50. Adequate fertilizers were applied, the ground was cleaned regularly and the process of harvesting was satisfactory.

The mean yield was studied year by year. During the period, Bourbon amarelo always attained first place while the other varieties varied in placing. The order of the varieties, in respect of the total yield for 1947-50, was: Bourbon amarelo (yellow Bourbon), Bourbon vermelho (red Bourbon), Sumatra, Maragogipe, Nacional and Amarelo de Botucatu.

The variety which was the earliest to produce mature fruits was Amarelo de Botucatu, followed by Sumatra, Nacional, Bourbon vermelho, Bourbon amarelo and finally Maragogipe.

The variety producing the largest seeds was Maragogipe: Nacional, Amarelo de Botucatu and Sumatra produced seeds of intermediate size, while the smallest were those of Bourbon vermelho and Bourbon amarelo.

The analysis of the data for the whole period of the trial, i. e., for sixteen harvests, shows the following:

a) the yield of Bourbon amarelo is significantly higher than that of Bourbon vermelho.

b) the yield of Bourbon vermelho is significantly higher than that of Sumatra.

c) the yield of Sumatra is significantly higher than those of Maragogipe, Nacional and Amarelo de Botucatu.

d) the yields of the last three do not differ significantly among themselves.

e) the rate of improvement of yield of Bourbon amarelo is greater than that of Bourbon vermelho.

f) the rate of improvement of yield of Maragogipe is greater than those of Nacional and Amarelo de Botucatu.

\section{LITERATURA CITADA}

1. Mendes, J. E. Teixeira. Ensaio de variedades de cafeeiros. Bol. Técn. Inst. Agr. do Estado de S. Paulo (Campinas) 65: 1-36. 1939.

2. Mendes, J. E. Teixeira. Ensaio de variedades de cafeeiros II. Bragantia 9: 81-101. 1949.

3. Krug, C. A. O cálculo da peneira média na seleção do cafeeiro. Revista do Instituto de Café do Est. de S. Paulo 15: 123-127. 1940.

4. Morales, A. Análise estatística do ensaio de variedades de cafê : Parte II. Bragantia 11 : 45-49, fig. 1-2. 1951. 